\title{
Isolation, production and characterization of fully human monoclonal antibodies directed to Plasmodium falciparum MSP10
}

Dominika J Maskus ${ }^{1,2}$, Susanne Bethke1 ${ }^{1}$, Melanie Seidel ${ }^{1}$, Stephanie Kapelski 1,2, Otchere Addai-Mensah'1,2,3, Alexander Boes ${ }^{1}$, Güven Edgü ${ }^{1}$, Holger Spiegel ${ }^{1}$, Andreas Reimann ${ }^{1}$, Rainer Fischer ${ }^{1,2}$, Stefan Barth ${ }^{1,4}$, Torsten Klockenbring ${ }^{1+}$ and Rolf Fendel ${ }^{1,2,4^{*+}}$

\begin{abstract}
Background: Semi-immunity against the malaria parasite is defined by a protection against clinical episodes of malaria and is partially mediated by a repertoire of inhibitory antibodies directed against the blood stage of Plasmodium falciparum, in particular against surface proteins of merozoites, the invasive form of the parasite. Such antibodies may be used for preventive or therapeutic treatment of $P$. falciparum malaria. Here, the isolation and characterization of novel human monoclonal antibodies (humAbs) for such applications is described.

Methods: B lymphocytes had been selected by flow cytometry for specificity against merozoite surface proteins, including the merozoite surface protein 10 (MSP10). After Epstein-Barr virus (EBV) transformation and identification of promising resulting lymphoblastoid cell lines (LCLs), human immunoglobulin heavy and light chain variable regions (Vh or VI regions) were secured, cloned into plant expression vectors and transiently produced in Nicotiana benthamiana in the context of human full-size $\operatorname{lgG} 1$ : . The specificity and the affinity of the generated antibodies were assessed by ELISA, dotblot and surface plasmon resonance (SPR) spectroscopy. The growth inhibitory activity was evaluated based on growth inhibition assays (GIAs) using the parasite strain 3D7A.
\end{abstract}

Results: Supernatants from two LCLs, 5 E8 and 5F6, showed reactivity against the second (5E8) or first (5F6) epidermal growth factor (EGF)-like domain of MSP10. The isolated $\mathrm{V}$ regions were recombinantly expressed in their natural pairing as well as in combination with each other. The resulting recombinant humAbs showed affinities of $9.27 \times 10^{-7} \mathrm{M}$ [humAb10.1 (H5F6:k5E8)], $5.46 \times 10^{-9} \mathrm{M}$ [humAb10.2 (H5F6:k5F6)] and 4.34 × 10-9 M [humAb10.3 (H5E8:k5E8)]. In GIAs, these antibodies exhibited $\mathrm{EC}_{50}$ values of $4.1 \mathrm{mg} / \mathrm{ml}$ [95\% confidence interval (Cl) $\left.2.6-6.6 \mathrm{mg} / \mathrm{ml}\right], 6.9 \mathrm{mg} / \mathrm{ml}$ (Cl $5.5-8.6 \mathrm{mg} / \mathrm{ml})$ and $9.5 \mathrm{mg} / \mathrm{ml}$ (Cl $5.5-16.4 \mathrm{mg} / \mathrm{ml})$, respectively.

Conclusion: This report describes a platform for the isolation of human antibodies from semi-immune blood donors by EBV transformation and their subsequent characterization after transient expression in plants. To our knowledge, the presented antibodies are the first humAbs directed against P. falciparum MSP10 to be described. They recognize the EGF-like folds of MSP10 and bind these with high affinity. Moreover, these antibodies inhibit P. falciparum 3D7A growth in vitro.

Keywords: EBV transformation, Human monoclonal antibodies, Plasmodium falciparum MSP10, Plant-based expression

\footnotetext{
*Correspondence: rolf.fendel@ime.fraunhofer.de

†Torsten Klockenbring and Rolf Fendel contributed equally to the article

${ }^{1}$ Fraunhofer Institute for Molecular Biology and Applied Ecology IME,

Aachen, Germany

Full list of author information is available at the end of the article
} 


\section{Background}

Malaria still claims over half a million victims each year and poses a significant burden to global health care and to the economy of endemic countries [1]. In humans, semi-immunity to clinical malaria develops slowly due to high allelic variations in many immuno-relevant plasmodial antigens, is incomplete and wanes quickly without frequent reinfections [2-4]. Several lines of defense contribute to the immune response against the erythrocytic stages of plasmodia, e.g. innate-like $\mathrm{V} \gamma 9: \mathrm{V} \delta 2 \mathrm{~T}$ cells [5] and anti-plasmodial antibodies. The repertoire and spectrum of antibodies which eventually can prevent clinical episodes of malaria gradually develops with cumulative exposure to infections [6-8]. Passive transfer of naturally acquired antibodies has been shown to reduce parasitaemia in infected individuals $[9,10]$. Such anti-plasmodial antibodies may mediate protection by prevention of re-invasion of merozoites into new erythrocytes [11], by antibody-dependent cellular inhibition mediated by monocytes $[3,12]$ and by antibody-dependent respiratory burst mediated by neutrophil granulocytes [13].

Most of the antibodies used for studies in the malaria field originate from rodents or rabbits. Unquestionably, these antibodies are valuable tools. However, they do not reflect the human immunoglobulin repertoire of semiimmune individuals. Malaria vaccine development is focusing on targets from the three major life cycle stages of the parasite in humans, the liver stage, the blood stage and the sexual stage. Sterile immunity, induced by experimental malaria infection, is mainly conferred by immune responses against the pre-erythrocytic stages [14]. However, immune responses in natural infection in hyperand holoendemic regions are primarily focused on the blood stage and the protection is incomplete [15]. Targets of this immune response mediating partial protection are mainly surface proteins of the merozoite stage. Members of the merozoite surface protein (MSP) family, the reticulocyte homology $(\mathrm{Rh})$ and the erythrocyte-binding like (EBL) proteins as well as the apical membrane antigen 1 (AMA1) play a central role. All of these proteins are in the focus of vaccine candidate studies [16]. One of the most recently identified members of the MSP family is MSP10. MSP10 was first described by Black et al., but until today there is little known about the function of this protein and whether it is essential [17]. Under the assumption that the genome of Plasmodium falciparum encodes more than one MSP that contains a double epidermal growth factor (EGF)-like domain, Black et al. sought to identify potential homologs of MSP1. It appears that MSP1 and MSP10 have several features in common; i.e. they share a double EGF-like domain and a glycosylphosphatidylinositol (GPI) anchor at their $\mathrm{C}$-terminus and both are mainly expressed during the later blood stages. Furthermore, MSP10 is also subject to proteolytic processing similar to MSP1, i.e. in the case of MSP10 starting from $30 \mathrm{~h}$ post invasion a product of $36 \mathrm{kDa}$ can be detected besides the intact protein of $80 \mathrm{kDa}$. Puentes et al. aimed at finding out if certain parts of MSP10 are capable of binding to erythrocytes and to inhibit the invasion of merozoites into new erythrocytes [18]. Three MSP10-derived 20-mer peptides showed these properties, thus arguing for a role of MSP10 in the attachment, re-orientation and/or invasion. Nevertheless, human monoclonal antibodies (humAbs) directed MSP10 have neither been generated nor characterized yet.

The aim of this work was to isolate MSP10-specific humAbs from semi-immune donors living in the Ashanti region in Ghana, a holoendemic area. Three humAbs, humAb10.1, humAb10.2 and humAb10.3, which are specific for either the first or the second EGF-like domain of MSP10, were isolated and characterized in detail.

\section{Methods}

\section{Recombinant plasmodial proteins}

The recombinant DsRed-fusion proteins featuring EGFlike domains 1 and 2 of MSP10 as well as EGF-like domains from related merozoite surface proteins MSP4 and MSP8 used in this study were produced transiently in Nicotiana benthamiana as previously described [19]. Additionally, two multidomain proteins were produced in a similar way, both containing the first EGF-like domain of MSP $1_{19}$ followed by the above-mentioned set of EGF-like domains of merozoite proteins (multi-EGF). The second multidomain molecule additionally included two blood-stage transcending proteins, Pfs 25 from the sexual stage and the TSR domain of CSP as a pre-erythrocytic stage component (Figure 1).

\section{Ethics statement and blood donors}

Ethical approval for this study was obtained from the Committee on Human Research Publication and Ethics (CHRPE) of the Kwame Nkrumah University of Science and Technology. Written informed consent was obtained from all participants after the goals of the study had been carefully explained. By the time of donation, the 31 volunteers were between 20 and 45 years old and had not had any reported malaria disease for 2 years. From each volunteer, $50 \mathrm{ml}$ of heparinized blood was drawn and prepared as described below.

\section{Preparation of peripheral blood monocytes (PBMCs) from Ghanaian donors}

PBMCs were prepared from $50 \mathrm{ml}$ of heparinized peripheral blood from each of the 31 donors. The blood was diluted in 1 volume of PBS before being layered onto 


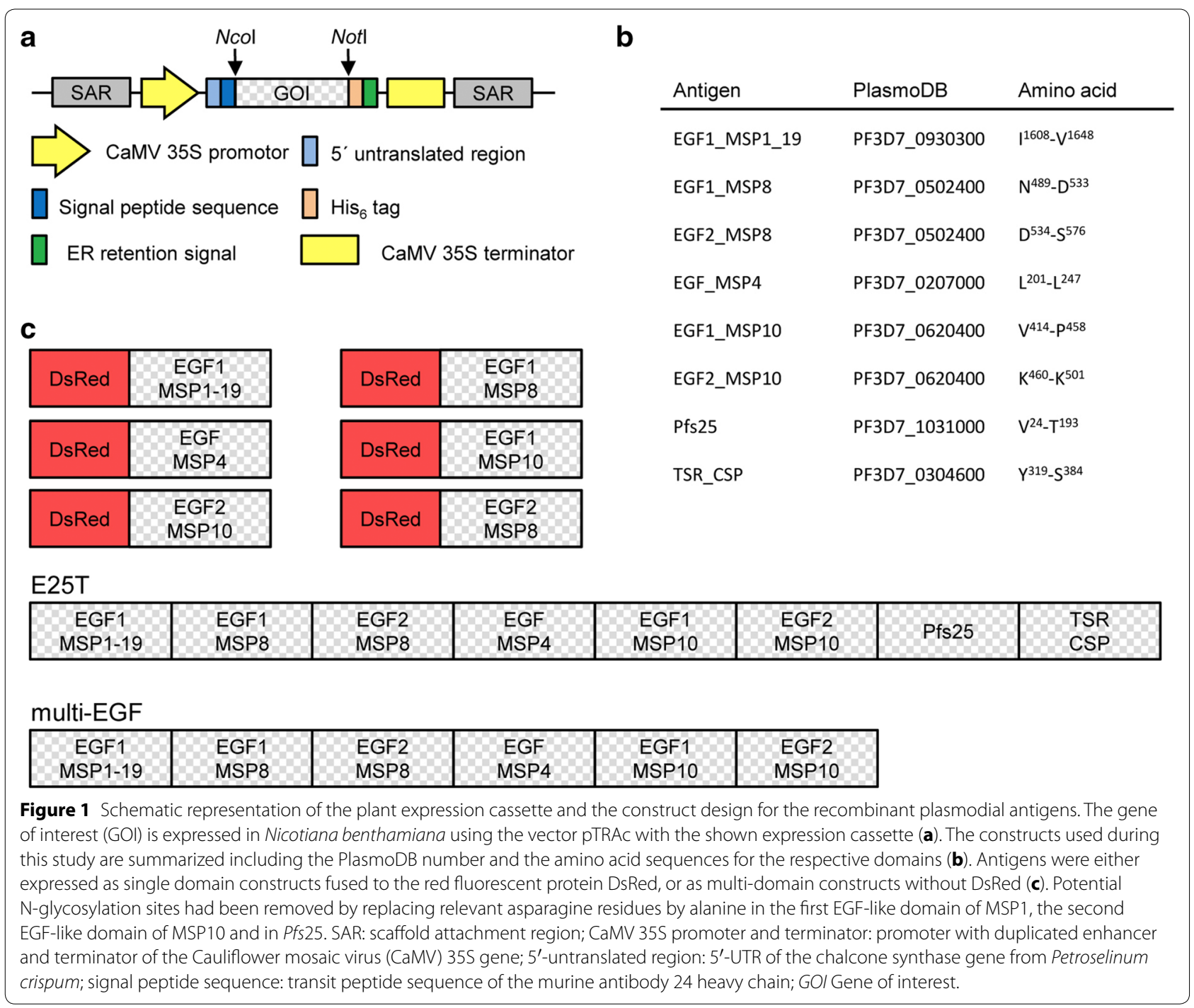

Ficoll (GE Healthcare, Uppsala, Sweden). After centrifugation $\left(800 \times g, 20 \mathrm{~min}, 25^{\circ} \mathrm{C}\right)$ the $\mathrm{PBMCs}$ in the interphase were harvested, washed once in PBS containing $1 \%(\mathrm{v} / \mathrm{v})$ FCS $\left(400 \times g, 10 \mathrm{~min}, 25^{\circ} \mathrm{C}\right)$ and once in PBS containing $10 \%(\mathrm{v} / \mathrm{v}) \mathrm{FCS}\left(300 \times g, 10 \mathrm{~min}, 25^{\circ} \mathrm{C}\right)$ before being cryopreserved in freezing medium $(10 \%(\mathrm{v} / \mathrm{v})$ DMSO in FCS) at cellular concentrations ranging from 3 to $6 \times 10^{6}$ cells $/ \mathrm{ml}$. The temperature was gradually decreased to $-80^{\circ} \mathrm{C}\left(1^{\circ} \mathrm{C} / \mathrm{min}\right)$ using isopropyl-containing freezing containers.

\section{ELISA}

The reactivity of Ghanaian plasma samples and antibodies in supernatants of lymphoblastoid cell lines (LCLs) against MSP10 was assessed by ELISA as described [20]. An amount of $100 \mathrm{ng}$ of the respective antigen was coated in wells of high-binding ELISA plates overnight at $4^{\circ} \mathrm{C}$.
Wells were washed three times with $0.1 \%(\mathrm{v} / \mathrm{v})$ Tween20 in PBS (137 mM NaCl, $2.7 \mathrm{mM} \mathrm{KCl}, 8.1 \mathrm{mM} \mathrm{Na}_{2} \mathrm{HPO}_{4}$, $\left.1.5 \mathrm{mM} \mathrm{KH}_{2} \mathrm{PO}_{4} ; \mathrm{pH} 7.4\right)$ and then blocked with $200 \mu \mathrm{l}$ $2 \%(\mathrm{w} / \mathrm{v})$ milk powder in PBS for $2-3 \mathrm{~h}$ at $37^{\circ} \mathrm{C}$. Following another three washing steps, $50 \mu$ l of each supernatant or diluted plasma sample was transferred to each well. As positive control, a dilution series of a mixture of four Ghanaian plasma samples was used. Plasma from European malaria-naïve blood donors served as negative control. Plates were then incubated at $37^{\circ} \mathrm{C}$ for $1 \mathrm{~h}$. After washing three times, goat-anti-human IgG conjugated to alkaline phosphatase (AP) (Dianova, Hamburg, Germany) in PBS $(1: 5,000)$ was added. After an incubation step at $37^{\circ} \mathrm{C}$ for $1 \mathrm{~h}$ and three washing steps, $p$-nitrophenyl phosphate was added. Absorbance at $405 \mathrm{~nm}$ was measured after $20-45 \mathrm{~min}$. Based on the reactivity of the positive control, a standard curve was fitted with 
a four-parameter logistic model, using the open-source software " $\mathrm{R}$ " for statistical computing [21].

\section{Fluorescent labelling of antigens}

For sorting of antigen-specific B cells, the multidomain protein E25T was conjugated to Alexa Fluor ${ }^{\circledR} 488$ using the "Alexa Fluor ${ }^{\circledR} 488$ 5-TFP" kit (Life Technologies, Darmstadt, Germany). Labelling efficiency was checked according to the manufacturer's instruction by absorbance measurements at $494 \mathrm{~nm}$ (Alexa Fluor ${ }^{\circledR} 488$ concentration) and $280 \mathrm{~nm}$.

\section{Reduction and alkylation of recombinant plasmodial proteins}

Recombinantly expressed plasmodial proteins were reduced in $5 \mathrm{mM} \mathrm{DTT}$ at $56^{\circ} \mathrm{C}$ for $45 \mathrm{~min}$ while shaking. The reactions were stopped by adding $15 \mathrm{mM}$ iodoacetamide. After incubation for $30 \mathrm{~min}$ in the dark, $5 \mathrm{mM}$ DTT were added to quench excessive iodoacetamide.

\section{Generation of Epstein-Barr virus (EBV)-containing supernatants from B95-8 cells}

Marmoset monkey lymphocytes B95-8 (\#ACC100, DSMZ, Berlin, Germany) were used to generate preparations of infectious EBV. To this end, cells were seeded at a density of $10^{6}$ cells $/ \mathrm{ml}$ and kept in RPMI 1640 with Glutamax $^{\mathrm{TM}}, 100 \mathrm{U} / \mathrm{ml}$ penicillin, $100 \mu \mathrm{g} / \mathrm{ml}$ streptomycin, 10\% (v/v) FCS for 4 to 11 days. After centrifugation $\left(800 \times g, 10 \mathrm{~min}, 25^{\circ} \mathrm{C}\right)$ supernatants were passed through sterile $0.45 \mu \mathrm{m}$-filters, snap frozen in liquid nitrogen and stored at $-80^{\circ} \mathrm{C}$.

\section{Flow cytometric cell sorting}

PBMCs from a semi-immune donor were thawed gently, washed once in RPMI 1640 containing 10\% (v/v) FCS and subjected to a staining procedure with a sterile mixture of AlexaFluor ${ }^{\circledR}$ 488-labelled antigen (E25T), anti-human IgG-RPE (BD Biosciences, Heidelberg, Germany) and anti-human CD22-APC (BD Biosciences) in labelling buffer (sterile PBS without $\mathrm{MgCl}_{2}$ and $\mathrm{CaCl}_{2}$ containing $2 \%(\mathrm{v} / \mathrm{v}) \mathrm{FCS}$ and $1 \mathrm{mM}$ EDTA, $\mathrm{pH} 7.4$ ) at $4^{\circ} \mathrm{C}$ for $30 \mathrm{~min}$ in the dark. Following three washing steps in ice-cold labelling buffer cells were filtered through a $33 \mu \mathrm{m}$-mesh, taken up in particle-free RPMI 1640 containing 10\% (v/v) FCS. CD22 ${ }^{+} / \mathrm{IgG}^{+}$antigen-specific mature $\mathrm{B}$ cells were sorted with a FACSAriaII cell sorter (BD Biosciences) and collected in RPMI 1640 containing 20\% (v/v) FCS.

\section{EBV transformation of antigen-specific B cells}

$B$ cells selected by cell sorting were then transformed as described before with minor modifications [22]. B cells were taken up in B cell medium (RPMI 1640 medium supplemented with L-glutamine, $10 \mathrm{mM}$ HEPES buffer, $1 \mathrm{mM}$ sodium pyruvate, $10 \%(\mathrm{v} / \mathrm{v})$ FCS), $1 \mu \mathrm{g} / \mathrm{ml}$ CpG2006 and 30\% (v/v) EBV-containing B95-8 supernatant $\left(3.4 \times 10^{8}\right.$ viral copies $\left./ \mathrm{ml}\right)$. An amount of $50 \mathrm{~B}$ cells was subsequently seeded onto 100,000 irradiated (83 gray) allogeneic PBMCs in 96 well round-bottom tissue culture plates and incubated at $37^{\circ} \mathrm{C}, 5 \% \mathrm{CO}_{2}$. After 2 weeks, supernatants were removed completely and replaced by B cell medium containing $1 \mu \mathrm{g} / \mathrm{ml} \mathrm{CpG} 2006$ and $50 \mathrm{U} / \mathrm{ml}$ rhIL-2 (Roche, Basel, Switzerland). After another week, supernatants were tested for secretion of total and specific IgG.

\section{Dotblot}

Dotblots were used to rapidly assess secretion of IgG by LCLs and to analyse the nature of MSP10 epitopes. In order to check for secreted total human IgG, $3 \mu$ l of the culture supernatants were transferred onto a nitrocellulose membrane (Roth, Karlsruhe, Germany) and allowed to dry for at least $15 \mathrm{~min}$. As positive control, a dilution series of a mixture of four Ghanaian plasma samples was used ranging from 1:100 to 1:3,200. Blocking was carried out in $5 \%(\mathrm{w} / \mathrm{v})$ non-fat milk powder in PBS for $30 \mathrm{~min}$ at $25^{\circ} \mathrm{C}$. Subsequently, the blocking buffer was substituted by a 1:5,000 dilution of goat-anti-human IgG-AP in $5 \%(\mathrm{w} / \mathrm{v})$ non-fat milk powder in PBS. Following incubation for $1 \mathrm{~h}$, the membrane was washed thoroughly with $0.05 \%(\mathrm{v} / \mathrm{v})$ Triton X-100 in PBS. Detection was carried out with NBT/BCIP. To determine whether conformational or linear epitopes of the antigens are recognized by the antibodies, native and reduced/alkylated antigens were applied onto nitrocellulose membranes.

\section{Spectratyping}

For the characterization of the LCL clonality, genomic DNA (gDNA) and RNA were used. The PCR conditions and the primers used have been described elsewhere [22]. As a monoclonal control gDNA from Ramos cells was used; gDNA from PBMCs served as a polyclonal control sample. Amplicons were analysed with a 3730 DNA Analyser (Applied Biosystems/Life Technologies).

\section{Rescue of human immunoglobulin variable regions}

RNA and gDNA were prepared either using the "NucleoSpin Tissue" and "NucleoSpin RNA II" kits (MachereyNagel, Düren, Germany) or the "RNeasy Plus Mini" kit (Qiagen, Hilden, Germany). Messenger RNA (mRNA) from LCLs was reverse transcribed using the "SuperScript III" kit (Life Technologies). Human heavy chain and light chain variable regions ( $\mathrm{Vh}$ and $\mathrm{Vl}$ regions) from LCLs were recovered as described before, with minor modifications [23]. Our approach differed in that mRNA from B cell clusters instead of from single cells was used. Moreover, (1) a re-amplification step with the primer set 
for the first PCRs was included and (2) these sequences were cloned into a TopoVector $\left(\mathrm{pCR}^{\circledR} \mathrm{II}-\mathrm{TOPO}^{\circledR}\right.$, Life Technologies) in order to be able to remove potential endogenous cleavage sites. All kits were used according to the manufacturers' instructions.

\section{Bioinformatic analysis of human immunoglobulin variable regions}

Variable regions were analysed in silico by the IMGT/VQUEST algorithm in order to determine the nature of the assembled V-, D- and J-gene segments and the germline homology [24]. The identity and similarity of the obtained $\mathrm{Vh}$ and $\mathrm{Vl}$ regions compared to their most closely related underlying germline sequences was determined by independently analyzing each of the underlying gene segments by an identity/similarity tool [25]. The respective complementarity determining regions (CDRs) were identified according to the Kabat rules [26]. Alignments were done with Clustal Omega [27]. Potential sulfation of tyrosine residues was predicted by the Sulfinator algorithm [28].

\section{Cloning}

All enzymes for cloning purposes were obtained from NEB (Frankfurt am Main, Germany). Amplicons from $\mathrm{V}$ regions were cloned into pTRAkt plant expression vectors. To reconstitute full-size heavy (IgG1) or light (Igк) chain genes, amplicons of the $\mathrm{Vh}$ region sequences from the second $V$ region-PCR were cloned into a suitable pTRAkt vector in frame with a sequence encoding a human IgG1 constant domain via AgeI/SalI; Vl-region sequences were cloned via AgeI and Bsi WI in frame with a sequence encoding a human Igא constant domain as previously described [29]. The resulting pTRAkt vectors were used for transformation of Agrobacterium tumefaciens (Rhizobium radiobacter) and subsequent transient expression of humAbs in Nicotiana benthamiana plants.

\section{Transient expression of recombinant human full-size IgG in Nicotiana benthamiana}

Electro-competent agrobacteria (Agrobacterium tumefaciens strain GV3101: pMP90RK with resistance to gentamycin, kanamycin and rifampicin) were transformed with one of the following pTRA vectors: pTRAc-p19si, pTRAkt_H_5E8, pTRAkt_H_5F6, pTRAkt_k_5E8, or pTRAkt_k_5F6 as previously described $[19,30]$. Plants were $8-10$ weeks old by the time of infiltration and had been raised in rock wool in a phytotron as described previously [30]. Plants were immersed into the agrobacterial suspension, infiltrated for $1 \mathrm{~min}$ at $5 \mathrm{kPa}, 25^{\circ} \mathrm{C}$ and then cultivated for 5 days with steady light and regular watering, i.e. spraying for 1 min every $3 \mathrm{~h}$. After 5 days of incubation the infiltrated plants were harvested. Leaves were shredded in two to three volumes of extraction

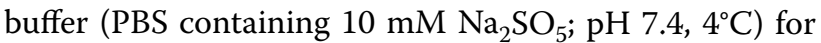
$1 \mathrm{~min}$. Insoluble material and plant fibers were removed by filtration through Miracloth. Then, $500 \mathrm{mM} \mathrm{NaCl}$ was added, $\mathrm{pH}$ was adjusted to 8.2 and the suspension was incubated at $4^{\circ} \mathrm{C}$ for $1 \mathrm{~h}$. Precipitated material was then removed by centrifugation $\left(17,000 \times g, 30 \mathrm{~min}, 4^{\circ} \mathrm{C}\right)$ and a successive filtration step using $0.45 \mu \mathrm{m}$-filters.

\section{Antibody purification by Protein A chromatography}

HumAbs were purified from Nicotiana benthamiana extracts as well as lymphoblastoid cell culture supernatants by Protein A chromatography using MabSelect ${ }^{\mathrm{TM}}$ $\mathrm{SuRe}^{\mathrm{TM}}$ Sepharose (GE Healthcare). The purification matrix was equilibrated with binding/washing buffer (0.2 $\mathrm{M}$ Tris- $\mathrm{HCl}, \mathrm{pH} 9.0)$ prior to the affinity chromatography. Antibodies were eluted with $0.2 \mathrm{M}$ Sodium Citrate, $\mathrm{pH} 2.5$, elution fractions were neutralized by $1 \mathrm{M}$ Tris, pH 9.0 and dialyzed against PBS. For use in in vitro growth inhibition assays (GIAs) antibodies were concentrated in RPMI 1640 incl. 25 mM HEPES (PAA, E15-041), using Vivaspin 15R 30,000 MWCO centrifugal concentrators (VWR 512-4124) and sterilized by filtration.

\section{Plasmodium falciparum culture}

Plasmodium falciparum strain 3D7A was cultured as described before [31]. Briefly, parasites were maintained at a haematocrit of $5 \%(\mathrm{v} / \mathrm{v})$ in parasite culture medium [RPMI 1640, $25 \mathrm{mM}$ HEPES, $2 \mathrm{mM}$ L-glutamine, $50 \mu \mathrm{g} /$ $\mathrm{ml}$ gentamycin, $10 \%(\mathrm{w} / \mathrm{v})$ Albumax ${ }^{\circledR} \mathrm{II}$ (Life Technologies)]. Erythrocytes of 12-16 individual donors, all having the blood group 0, Rh-positive, were obtained in CPDA tubes from the Department for Transfusion Medicine, RWTH Aachen University Clinic, Aachen, Germany. The suspensions were mixed, centrifuged in order to remove plasma and white blood cells $(650 \times g, 5 \mathrm{~min}$, $25^{\circ} \mathrm{C}$, without break) and washed for three times in SAGmannitol $(150 \mathrm{mM} \mathrm{NaCl}, 50 \mathrm{mM}$ D-glucose, $1.2 \mathrm{mM}$ adenine, $28.8 \mathrm{mM} \mathrm{D}(-)$-mannitol). Washed erythrocytes were taken up in SAG-mannitol to obtain a final haematocrit of $66.6 \%(\mathrm{v} / \mathrm{v})$.

\section{In vitro growth inhibition assay (GIA)}

In vitro growth inhibition of the isolated antibodies was assessed via GIA on P. falciparum as described before using humAbs in final concentrations ranging from 10 to $0.078 \mathrm{mg} / \mathrm{ml}$ in RPMI 1640 containing $25 \mathrm{mM}$ HEPES [32]. As positive control, $6 \mathrm{mg} / \mathrm{ml}$ polyclonal rabbit-antiAMA1 IgG (BG98) was used [33]. As corresponding negative control $6 \mathrm{mg} / \mathrm{ml}$ polyclonal IgG of a naïve rabbit were used. The humAb 2G12, an HIV-1-specific IgG, was taken as a plant-expressed non-specific control [34]. P. falciparum 3D7A were synchronized by three sorbitol treatments 7, 5 and 3 days prior to the GIA [35]. Schizont 
stage parasites were seeded at 0.3 or $0.4 \%$ parasitaemia in $2 \%(\mathrm{v} / \mathrm{v})$ haematocrit. Each GIA was performed with $50 \mu \mathrm{l}$ final volume in 96-well flat-bottom half-area culture plates. After an incubation period of $44 \mathrm{~h}$, GIAs were harvested and frozen at $-20^{\circ} \mathrm{C}$ for at least $16 \mathrm{~h}$. Parasite growth was estimated by a pLDH-assay [36]. The percentage of relative growth inhibition was calculated as follows: \% inhibition $=100 \times\left[\mathrm{A}_{655 \mathrm{~nm}}\right.$ (sample) $-\mathrm{A}_{655 \mathrm{~nm}}$ (erythrocyte control)]/[ $\mathrm{A}_{655 \mathrm{~nm}}$ (schizont growth control) $-\mathrm{A}_{655 \mathrm{~nm}}$ (erythrocyte control)].

\section{Immunofluorescence assay}

Synchronous $P$. falciparum 3D7A were used to prepare IFA slides. Smeared parasites were fixed in methanol at $-20^{\circ} \mathrm{C}$ for $10 \mathrm{~min}$. After blocking in $1 \%$ (v/v) FCS (low IgG) in PBS for $3 \mathrm{~h}$ at $25^{\circ} \mathrm{C}$, slides were incubated with $50 \mu \mathrm{g} /$ $\mathrm{ml}$ mouse-anti-MSP4 and either of the three human-antiMSP10 antibodies (10 or $25 \mu \mathrm{g} / \mathrm{ml}$ ) or 2G12 (an anti-gp 120 HIV-1 humAb as isotype control for human IgG) in $1 \%(\mathrm{v} / \mathrm{v})$ FCS (low IgG), 0.01\% (w/v) Saponin in PBS) in a moist box at $25^{\circ} \mathrm{C}$ for $1 \mathrm{~h}$. After four washing steps in PBS, the slides were treated with 1:100 goat-anti-mouse IgG(H + L)-Alexa Fluor ${ }^{\circledR} 488$ (Life Technologies), 1:1,000 goat-anti-human IgG(H $+\mathrm{L})$-Cy3 (Dianova) and $10 \mu \mathrm{g} /$ $\mathrm{ml}$ Hoechst 33342 (Life Technologies) in a moist box at $25^{\circ} \mathrm{C}$ for $1 \mathrm{~h}$. Five washing steps were carried out. Prolong ${ }^{\circledR}$ Antifade mounting medium (Life technologies) was used to conserve the staining. Images were taken at a $630 \times$ magnification with a Leica TCS SP8 microscope and LAS AF Version 3.1.3 software (Leica, Solms, Germany).

\section{Surface plasmon resonance (SPR) spectroscopy}

Kinetic binding parameters of the monoclonal antibodies were analysed by SPR spectroscopy using a Biacore T200 instrument (Biacore, GE Healthcare, Uppsala, Sweden) and Protein A-functionalized CM5-S series sensor chips as previously described [29]. For kinetic analysis, 100-180 RU of the different humAbs were captured onto immobilized protein A and recombinant multi-EGF (0.1$540 \mathrm{nM}$ ) was injected at a flow rate of $30 \mu \mathrm{l} / \mathrm{min}$ for $180 \mathrm{~s}$. Dissociation was tracked for $600 \mathrm{~s}$. Between measurements, the surface was regenerated by pulsing for $1 \mathrm{~min}$ with $30 \mathrm{mM} \mathrm{HCl}$. Buffer injections were used for double referencing. All measurements were performed at $25^{\circ} \mathrm{C}$ using HBS-EP $(10 \mathrm{mM}$ Hepes, $150 \mathrm{mM} \mathrm{NaCl}, 3.4 \mathrm{mM}$ EDTA, 0.005\% (v/v) Tween-20) as running buffer. Binding curves were evaluated using BIAEval 4.0 (GE Healthcare).

\section{Results}

Reactivity of plasma from Ghanaian semi-immune donors against MSP10 EGF-like domains

The study was designed to efficiently isolate humAbs which recognize the EGF-like domains of MSP10 and which represent a part of the naturally-acquired, protective immunoglobulin repertoire of semi-immune donors. The definition of semi-immunity of the plasma donors was primarily based on observation that they had not shown any signs of clinical malaria for 2 years. Moreover, several screenings had been performed to make sure that the set of donors had a broad anti-malarial antibody response, as published before [13, 19, 30, 37-39].

To quantify the MSP10-response, plasma of 31 Ghanaian blood donors were screened for reactivity against DsRed-MSP10(EGF1) (Figure 2a) and DsRedMSP10(EGF2) (Figure 2b). In order to exclude background binding of the plasma samples against the fusion partner DsRed, background reactivity against DsRed was measured as well and subtracted from the reactivity against the respective fusion protein (Figure 3a). In this ELISA, 15 plasma samples (48\%) showed specific reactivity (>reactivity of negative control $+2 \times$ standard deviations) against DsRed-MSP10(EGF1); 15 (48\%) showed specific reactivity against DsRed-MSP10(EGF2). Interestingly, eleven of these recognized both EGF-like domains of MSP10. Therefore, B cells from these individuals appeared to be a suitable source of pan-MSP10 EGF-like domain humAbs.

It had been reported that naturally acquired antibodies which are specific for plasmodial EGF-like domains primarily react with conformational epitopes [17, 40, 41]. Thus, these data were especially confirmed for MSP10. To this end, native as well as reduced and alkylated form of the multi-EGF fusion protein, containing both EGF-like domains of MSP10, was used for an ELISA with 13 of the Ghanaian plasma samples which were positive for either or both EGF-like domains of MSP10 (Figure 3b). The reactivity of each of the semi-immune plasma samples was reduced to background level when the antigen had been reduced and/or alkylated demonstrating that IgG of the semi-immune donors specifically recognize conformational epitopes of the MSP10 EGF-like domains.

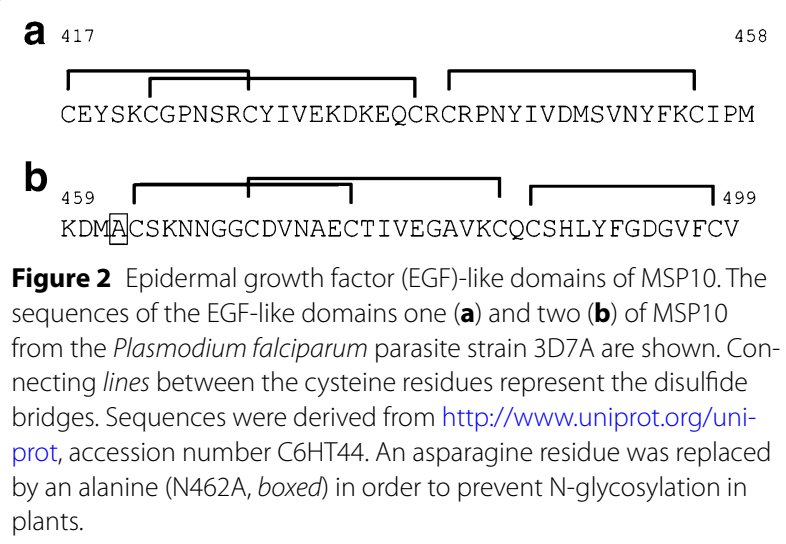



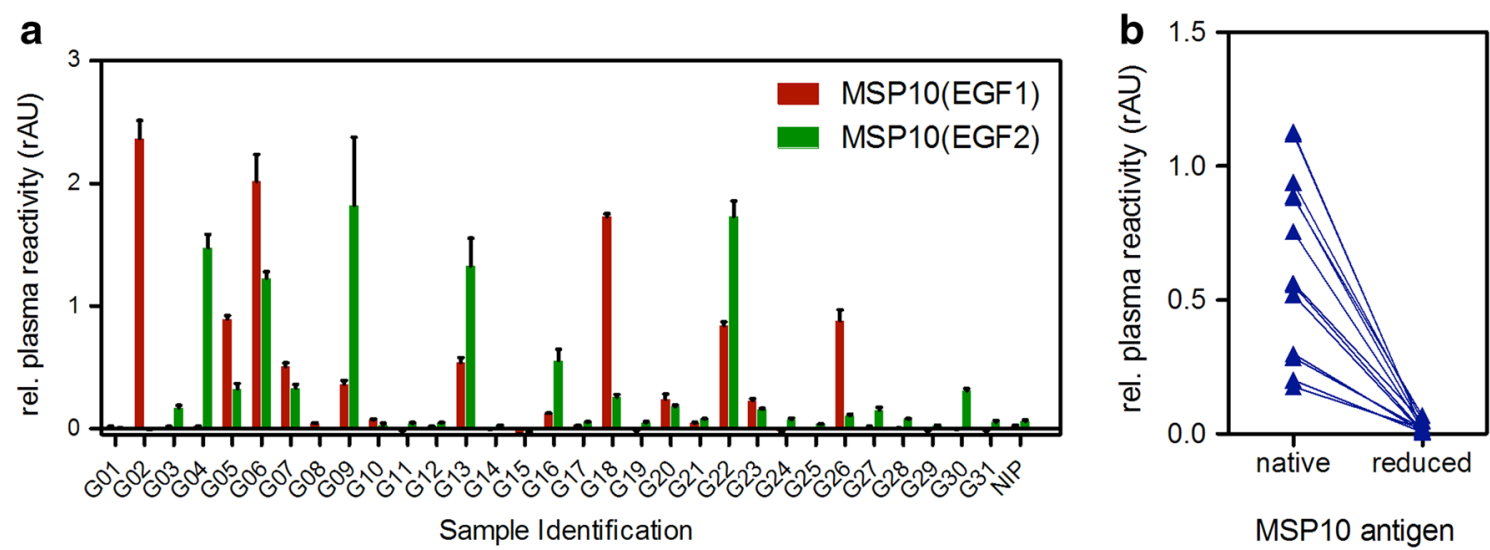

Figure 3 Reactivity of Ghanaian plasma samples against both EGF-like domains of MSP10. a Reactivity of 31 Ghanaian plasma samples and a European non-immune control plasma pool (NIP) were tested against the first (red bars) or second (green bars) EGF-like domain of MSP10 by ELISA. Reactivities were measured against the DsRed-MSP10(EGF) fusion protein. Thus, the background reactivity against DsRed, which was very low in all samples (absorbance at $405 \mathrm{~nm}$ below 0.1), was subtracted from all samples. Values represent relative reactivities in comparison to the positive control pool, whose reactivity was set to "1". b Plasma samples positively reacting to MSP10 were also tested for reactivity against the reduced and alkylated antigen multi-EGF. All data were measured in technical triplicates. Error bars represent the standard deviation of sample results.

\section{Selection and EBV transformation of mature $\lg \mathrm{G}^{+}$ antigen-specific $B$ cells}

For selection of mature, $\operatorname{IgG}^{+}$, merozoite surface antigenspecific B cells as basis for the subsequent EBV transformation, PBMCs from donor G13, one of the donors whose plasma reacted with both of the MSP10 EGFlike domains, were used. An amount of $1.25 \times 10^{7}$ vital PBMCs was subjected to flow cytometric sorting and 4,869 vital $\mathrm{CD}_{22} 2^{+} \mathrm{IgG}^{+} \mathrm{B}$ cells $(0.039 \%)$ were selected and seeded for EBV transformation. After 7 weeks, 6 out of 90 wells $(6.67 \%)$ showed reactivity with the multidomain fusion protein E25T, which includes both EGFlike domains of MSP10. The corresponding LCLs were expanded. Fifteen weeks after EBV transformation four of these six cultures had ceased to secrete specific IgG. The remaining two cultures, 5E8 and 5F6, were used for clonal analyses by spectratyping and rescue of $\mathrm{Vh}$ and $\mathrm{Vl}$ sequences by PCR.

Spectratyping revealed that LCL 5F6 was monoclonal as early as 16 weeks post infection. At that time point LCL 5E8 was still octaclonal. After continuous subculturing of the LCL 5E8 for another 21 weeks, it also became monoclonal.

\section{Rescue and analysis of antibody variable sequences}

Each of the LCLs 5E8 and 5F6 were subjected to RNA isolation, cDNA synthesis and amplification of immunoglobulin Vh-, Vk- and Vl- region sequences. From each culture, one Vh and one Vk were recovered. Subsequently, the $\mathrm{Vh}$ and $\mathrm{Vl}$ regions were sequenced and compared to the closest corresponding germline sequences. As shown in Figure 4, 60 DNA mutations in the Vh
5E8 sequence and $>40$ DNA mutations in the Vl 5E8 sequence led to 31 and 16 amino acid changes, respectively (Figure 4a, b). Sequence alignments for Vh $5 \mathrm{~F} 6$ (Figure 4c) and Vl 5F6 (Figure 4d) revealed 21 changes ( $\geq 45$ DNA mutations) and 12 changes ( $\geq 26$ DNA mutations), respectively.

\section{Recombinant expression of humAbs}

Variable region sequences of 5E8 and 5F6 were cloned into pTRAkt vectors for recombinant transient expression in Nicotiana benthamiana. Since antibody heavy and light chains are encoded on separate pTRAkt plant expression plasmids it is possible to realize any $\mathrm{HC} / \mathrm{LC}$ combination. After initial small scale expression studies three (H5F6:К5E8, H5F6:К5F6 and H5E8:к5E8) of the four possible $\mathrm{Vh} / \mathrm{Vl}$ combinations recognized MSP10. Subsequently, the three corresponding binding-competent humAbs were transiently expressed at a medium scale (10-16 Nicotiana benthamiana plants). Heavy chain 5F6 (H5F6) was either co-expressed with the light chain $5 \mathrm{E} 8(\kappa 5 \mathrm{E} 8)$ or $5 \mathrm{~F} 6(\kappa 5 \mathrm{~F} 6)$, respectively, resulting in humAb10.1 (H5F6:K5E8) and humAb10.2 (H5F6:k5F6). Heavy chain 5E8 (H5E8) was co-expressed with its natural light chain ( $\kappa 5 \mathrm{E} 8)$, thus forming humAb10.3 (H5E8:K5E8). The average yield of the recombinant antibodies was 100-200 mg per kg of fresh leaf material.

Specific binding comparison between antibodies from $\mathrm{LCL}$ supernatants and respective recombinant humAbs

The reactivity of the humAbs against MSP10(EGF1) and MSP10(EGF2) was verified by ELISA with DsRedMSP10(EGF1), DsRed-MSP10(EGF2) and multi-EGF 


\section{a \\ $5 \mathrm{E} 8$ Vh germline_Vh \\ $5 \mathrm{E} 8$ Vh germline_Vh \\ b \\ $5 \mathrm{E} 8 \mathrm{VI}$ germline_Vl \\ $5 \mathrm{E} 8 \mathrm{VI}$ germline_Vl \\ C \\ 5F6_Vh \\ germline_Vh \\ $5 \mathrm{~F} 6$ - Vh germline_Vh}

\section{d} 5F6_Vl
germline_Vl

$5 \mathrm{~F} 6$ V 1 germline_Vl

QVQLQESGPGLVKPSETLFLTCSVS LRSMSDYYWSWVRQPAGKGLEWMGRITAPGTTNYNLKFNN QVQLQESGPGLVKPSETLSLTCTVSGGSISSYYWSWIRQPAGKGLEWIGRIYTSGSTNYNPSLKS

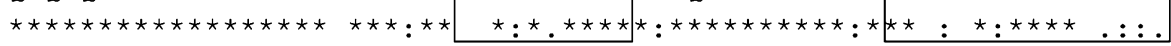

CDR3 RLSMSVDTSRNLVSLRLTSVTAADTAVYYCTRDAHNYGRGLDYWGQGKLVTVSS RVTMSVDTSKNQFSLKLSSVTAADTAVYYCARXXXXDSSGXDSWGQGTLVTVSS

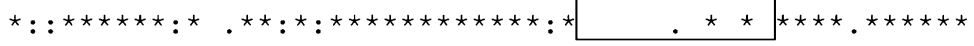

CDR1 $C D R 2$ EIVLTQSPDILSLSPGERATLSCRASQALTAKYLAWYQQKPGQVPRLLIY GSSTRATGI PDRFRG EIVLTQSPGTLSLSPGERATLSCRASQSVSSSYLAWYQQKPGQAPRLLIYGASSRATGIPDRFSG

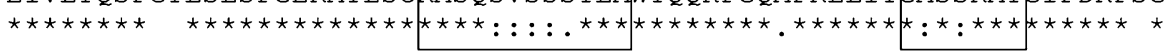
CDR3 SGSGTDFTLTISRLEPADSAVYYC QQYEDSPWTFGQGTKVELK SGSGTDFTLTISRLEPEDFAVYYCQQYGSSPWTFGQGTKVEIK

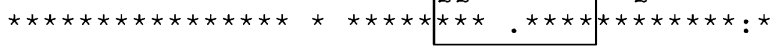

CDR1 $20 R 2$ EVQLVESGGDLVKPGGSLRLSCVVS GERISTSAMSWVRQVPGKGLEWVSPISESGGSKDYADSVR EVQLVESGGGLVQPGGSLRLSCAAS GFTFSSYAMSWVRQAPGKGLEWVSAISGSGGSTYYADSVK

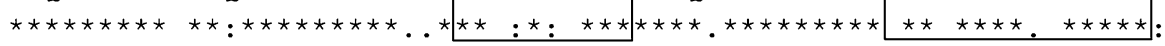
CDR3

GRFTISRDTSKNTLYLQMNSLGADDTALYYCAKSVGYFDTSGYYRWDYFDSWGQGTLVTVSS GRFTISRDNSKNTLYLQMNSLRAEDTAVYYCAKXXXYYDSSGYYXXXYFDYWGQGTLVTVSS

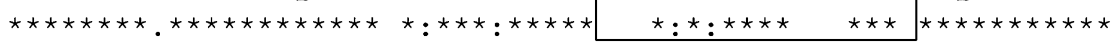

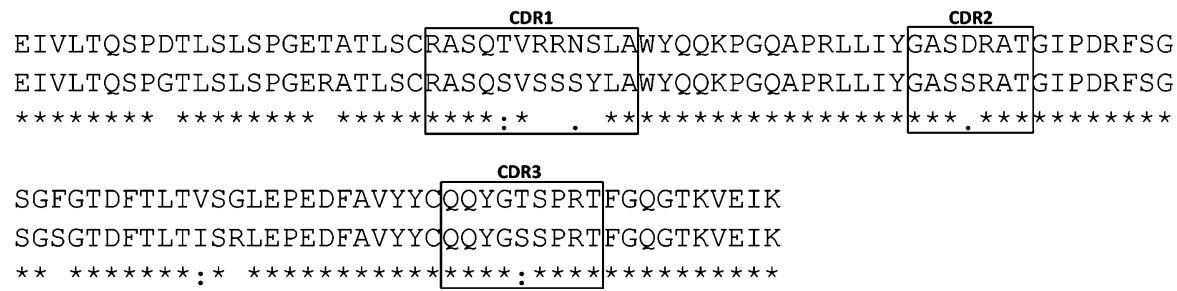

Figure 4 Alignment of $\mathrm{Vh}$ and $\mathrm{VI}$ sequences of $5 \mathrm{E} 8$ and $5 \mathrm{~F} 6$ with their respective germline sequence. The amino acid sequences of the obtained human antibody $\mathrm{V}$ region sequences rescued from LCLs $5 E 8(\mathbf{a}, \mathbf{b})$ and $5 F 6(\mathbf{c}, \mathbf{d})$ were aligned to their respective germline sequence, as obtained by the IMGT/N-Quest Tool [24]. Joining region elements containing N-nucleotides between the V-, D and J-segments for the Vh $(\mathbf{a}, \mathbf{c})$ are marked by the undefined amino acid X. CDR1-3 (boxes) are labelled according to the Kabat definition.

comprising both EGF-like domains of MSP10. All humAbs bound to multi-EGF (Figure 5). The recombinant humAb10.3 and the homologous LCL 5E8 supernatants similarly reacted with MSP10(EGF2), but not MSP10(EGF1). Likewise and complementarily, LCLderived IgG 5F6 and recombinant humAb10.2 recognized MSP10(EGF1), but not MSP10(EGF2). The shuffled antibody humAb10.1, which by definition could only be recombinantly expressed, recognized the first EGF-like domain of MSP10 and thus showed the same specificity as humAb10.2.

The affinity of the humAbs to MSP10 was analysed by SPR spectroscopy using the multi-EGF fusion protein, which is monovalent and contains several EGFlike domains of the MSP family including both EGF-like domains of MSP10. Kinetic constants $k_{a}, k_{d}$ and $K_{D}$ of both humAb10.2 and humAb10.3, produced in different expression systems, were determined. The $K_{D}$ values of all antibodies are summarized in Table 1. High association rates $\left(k_{\mathrm{a}}\right)$ for both humAb10.2 and humAb10.3 were observed. However, the dissociation rate $\left(k_{d}\right)$ of humAb10.3 was lower than the one of humAb10.2, indicating that humAb10.3 possesses a higher affinity for MSP10(EGF2) than humAb10.2 for MSP10(EGF1). The affinity of the humAb10.1, which is composed of the artificial combination of H5F6:א5E8, to its antigen MSP10(EGF1) was more 


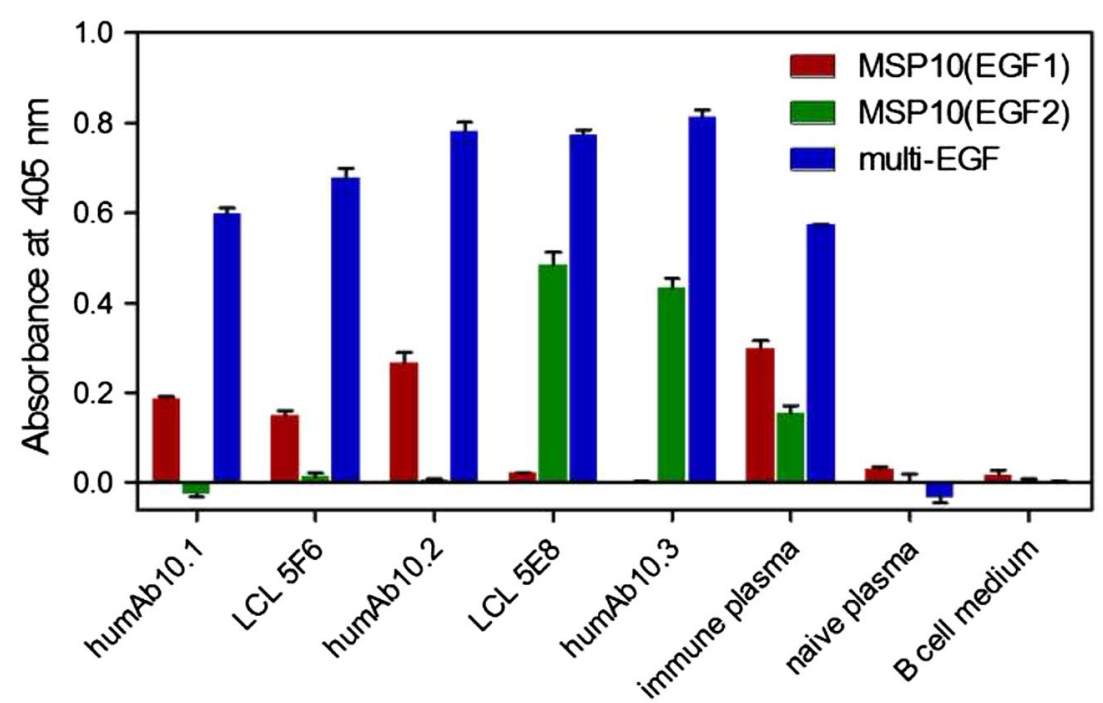

Figure 5 Specific reactivity of antibodies produced by the LCLs versus their derived recombinant humAbs. Using ELISA, the specific reactivity of the antibodies from the supernatant of LCLs (undiluted, three-day culture) as well as the derived recombinant humAbs transiently produced in Nicotiana benthamiana against the first (red bars) or second (green bars) EGF-like domain of MSP10 and multi-EGF containing a series of plasmodial EGF-like domains (blue bars). Represented values reflect the reactivity against the fusion proteins corrected by the reactivity observed with the his-tagged control protein (DsRed). Recombinantly expressed and purified humAb10.1 (H5F6:k5E8), humAb10.2 (H5F6:k5F6) and humAb10.3 (H5E8:k5E8) were applied in concentrations of 150,1.5 and $3 \mu \mathrm{g} / \mathrm{ml}$, respectively. A pool of Ghanaian plasma samples at a dilution of 1:200 served as positive control, a pool of naïve plasma samples as negative control. Plain B cell medium was used as negative control for the LCL. The ELISA was performed in technical triplicates; the error bars represent the standard deviations.

Table 1 Affinities ( $K_{D}$ values) of purified humAb10.1, humAb10.2 and humAb10.3 as determined by SPR spectroscopy using the recombinant MSP-based fusion protein multi-EGF

\begin{tabular}{|c|c|c|c|c|}
\hline Antibody & $\begin{array}{l}\text { Expression } \\
\text { system }\end{array}$ & $K_{a}\left(M^{-1} s^{-1}\right)$ & $K_{d}\left(s^{-1}\right)$ & $\mathrm{K}_{\mathrm{D}}(\mathrm{M})$ \\
\hline $\begin{array}{l}\text { humAb10.1 } \\
\text { (H5F6:k5E8) }\end{array}$ & $\begin{array}{l}\text { Nicotiana } \\
\text { benthami- } \\
\text { ana }\end{array}$ & $4.43 \times 10^{3}$ & $4.11 \times 10^{-3}$ & $9.27 \times 10^{-7}$ \\
\hline \multirow[t]{2}{*}{$\begin{array}{l}\text { humAb10.2 } \\
\text { (H5F6:k5F8) }\end{array}$} & $\begin{array}{l}\text { Nicotiana } \\
\text { benthami- } \\
\text { ana }\end{array}$ & $5.31 \times 10^{5}$ & $2.90 \times 10^{-3}$ & $5.46 \times 10^{-9}$ \\
\hline & LCL 5 F6 & $4.46 \times 10^{5}$ & $2.95 \times 10^{-3}$ & $6.62 \times 10^{-9}$ \\
\hline \multirow[t]{2}{*}{$\begin{array}{l}\text { humAb10.3 } \\
\text { (H5E6:k5E8) }\end{array}$} & $\begin{array}{l}\text { Nicotiana } \\
\text { benthami- } \\
\text { ana }\end{array}$ & $2.32 \times 10^{5}$ & $1.15 \times 10^{-3}$ & $5.39 \times 10^{-9}$ \\
\hline & LCL $5 E 8$ & $3.99 \times 10^{5}$ & $3.06 \times 10^{-4}$ & $8.04 \times 10^{-10}$ \\
\hline
\end{tabular}

than 100-fold lower than the affinity of humAb10.2 for the same antigen. The recombinant humAb10.2 and the corresponding LCL-derived 5F6 antibody showed a comparable affinity to the antigen MSP10(EGF1). Surprisingly, the affinity of the humAb10.3 expressed in plants differs by a factor of seven from the respective antibody produced by the corresponding LCL (5E8).

A potential explanation for this difference might be a posttranslational modification of the antibody, e.g. the sulfation of tyrosine residues, which is assumed not to take place in plants [42]. Therefore, in silico analysis was performed using the Sulfinator tool [28]. Two residues in the CDR1 (LRSMSDYY) and one residue in the CDR3 (DSAVYYCQQYED) of the heavy chain of humAb10.3 were predicted to be sulfated in mammalian expression systems.

\section{Recognition of conformational epitopes of humAb10.1, humAb10.2 and humAb10.3}

Knowing that antibodies of the protective immunoglobulin repertoire of semi-immune individuals mainly recognize correctly folded plasmodial EGF-like domains as shown in Figure $3 \mathrm{~b}$ and by others [17, 40, 41], antibodies humAb10.1, humAb10.2 and humAb10.3 were tested for their binding capacities against conformational epitopes of different members of the merozoite surface protein family and MSP10. Analysis by dotblots showed that all three humAbs bound conformational epitopes of MSP10(EGF1) or MSP10(EGF2), respectively, but did not bind to their reduced counterparts. Moreover, they did not cross-react with other plasmodial EGF-like domains of MSP1, MSP4 or MSP8.

In conclusion, all human antibodies described here only bind the native antigen, thus recognizing a conformational epitope. Secondly, all three antibodies bind highly specific to MSP10 EGF-like domains, and do not show any cross-reactivity (Figure 6). 


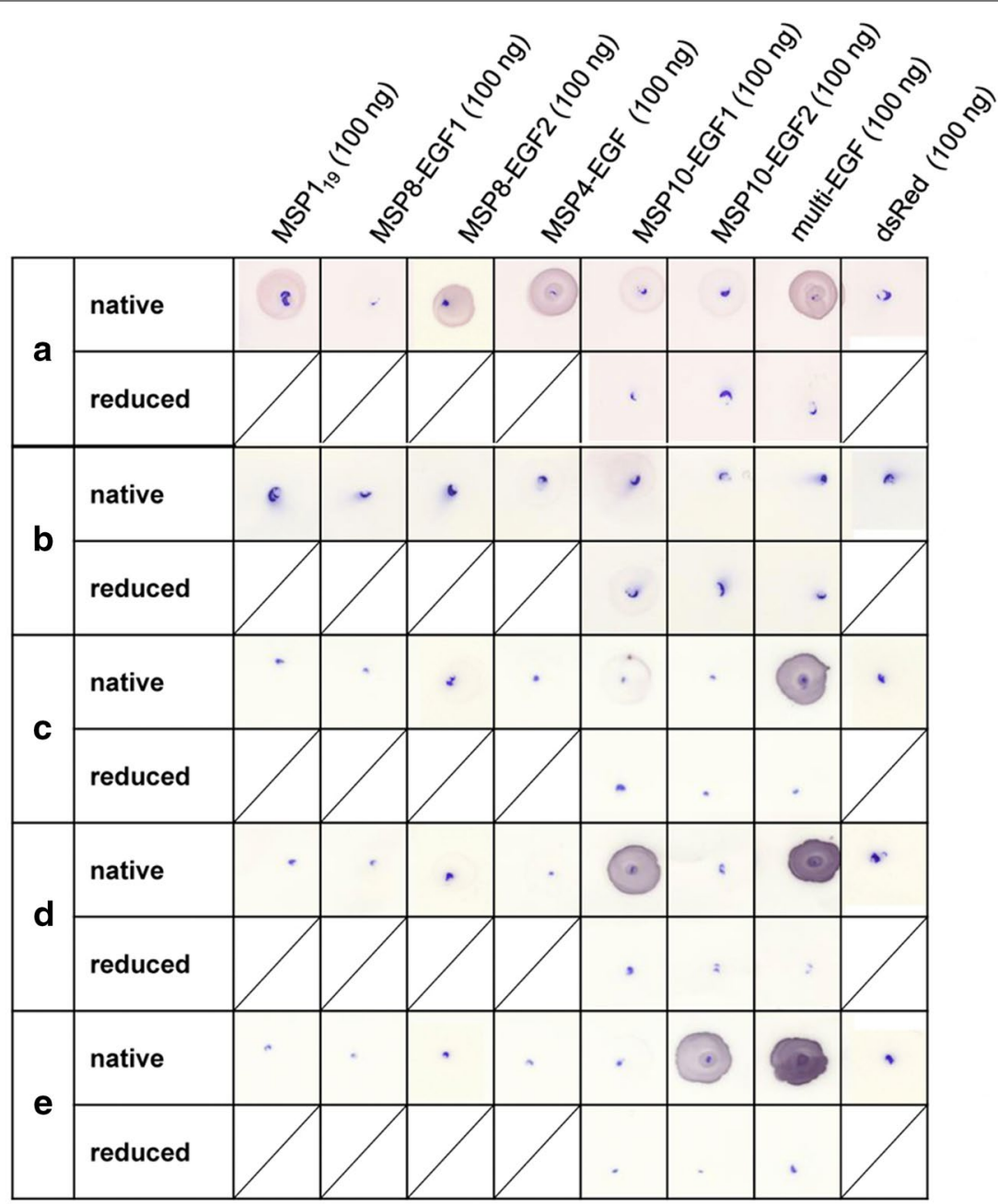

Figure 6 Dotblots with native and reduced EGF-like domains of P. falciparum merozoite surface proteins. Native proteins MSP $1_{19}$, DsRed-fusion proteins of MSP8(EGF1), MSP8(EGF2), MSP4(EGF), MSP10(EGF1) and MSP10(EGF2), multi-EGF and DsRed were applied in the indicated amounts. Proteins containing any of the EGF-like domains of MSP10 were also reduced and alkylated and used in the same quantity. The Ghanaian plasma pool (a) and the naïve plasma pool (b) were used in a 1:500 dilution. Recombinantly expressed and purified humAb10.1 (c), humAb10.2 (d) and humAb10.3 (e) were used in concentrations of 100, 50 and $1.4 \mu \mathrm{g} / \mathrm{ml}$, respectively. As secondary antibody, goat-anti-human lgG-AP (Dianova) at a dilution of 1:5,000 was used.

\section{IFA of the anti-MSP10 humAbs}

In order to validate, if the antibodies not only recognize recombinantly produced EGF-like domains of MSP10, but also naturally expressed MSP10, we performed immunofluorescence assays. To this end, segmented P. falciparum 3D7A schizonts were used for confocal microscopy with humAb10.1, humAb10.2 and humAb10.3 (Figure 7). As counterstain, a murine monoclonal MSP4(EGF)-specific antibody was used [29]. As an isotype control of human IgG, the anti-gp 120 HIV-1 humAb 2 G12 instead of the MSP10-specific humAb was used. No signal was detected in this setup. HumAb10.1 (Figure 7a), humAb10.2 (Figure 7b) and humAb10.3
(Figure 7c) showed partial co-localization with the antiMSP4 antibody. Additionally, the humAbs recognized a dot-like structure at the apical end of the preformed merozoites in the schizont stage.

\section{Inhibition of $P$. falciparum 3D7A growth by MSP10-specific} humAbs in vitro

In order to test the inhibitory potential of humAb10.1, humAb10.2 and humAb10.3, an in vitro-GIA with P. falciparum strain 3D7A was performed. All three antibodies showed a concentration-dependent inhibition of $P$. falciparum 3D7A (Figure 8). However, an inhibition of $100 \%$ was not reached by any of the antibodies at the applied 


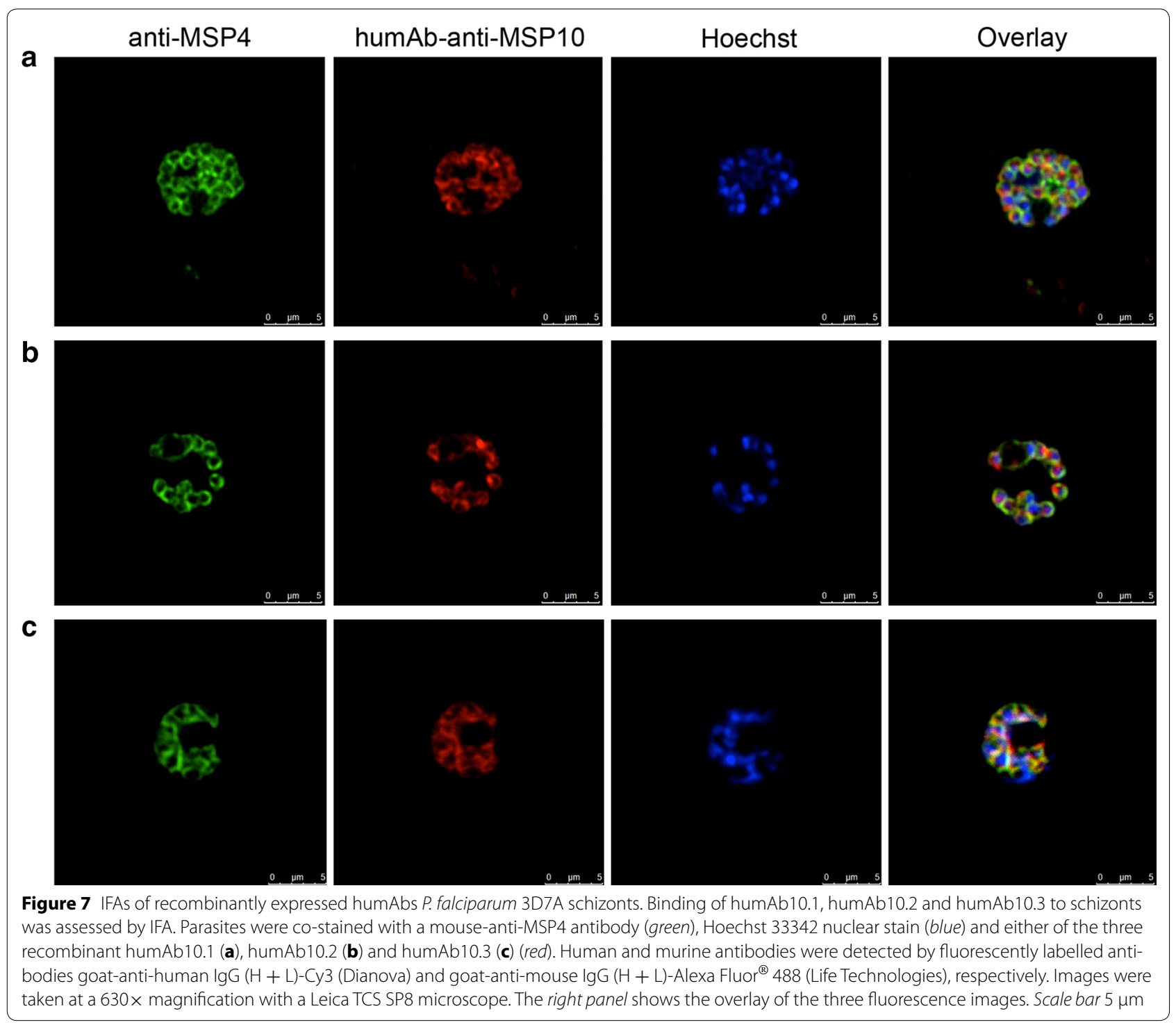

concentrations; the maximum inhibition of all antibodies ranged between 60 and $70 \%$. HumAb10.1 inhibited $P$. falciparum 3D7A most efficiently with an $\mathrm{EC}_{50}$ value of $4.1 \mathrm{mg} / \mathrm{ml}$ (95\% confidence interval (CI) $2.6-6.6 \mathrm{mg} / \mathrm{ml}$ ), humAb10.2 inhibited the parasite growth with an $\mathrm{EC}_{50}$ value of $6.9 \mathrm{mg} / \mathrm{ml}$ (CI $5.5-8.6 \mathrm{mg} / \mathrm{ml}$ ) and humAb10.3 inhibited the merozoite invasion with at an $\mathrm{EC}_{50}$ value of $9.5 \mathrm{mg} / \mathrm{ml}$ (CI $5.5-16.4 \mathrm{mg} / \mathrm{ml})$.

\section{Discussion}

So far, only a handful of anti-plasmodial humAbs have been isolated and described. Some of these are specific for the MSPs (MSP1, MSP2 and MSP3) or GLURP [4346]. Others show specificity for the plasmodial proteins expressed on the erythrocyte surface, such as VAR2CSA,
RESA and the Plasmodium vivax DBP [47-49]. Another work also describes humAbs specific for the sexual stage of the parasite (Pfs48/45) or the sporozoite stage $\left((\mathrm{NPNA})_{3}\right.$-repeat of CSP) $[50,51]$.

Here, additional human antibodies specific for the merozoite surface, isolated by an innovative human antibody technology platform, are presented. This technology combines the screening of naturally exposed semi-immune individuals from endemic countries for antigen-specific reactivity, the targeted selection of antigen-specific B cells by flow cytometric sorting, the subsequent EBV transformation, rescue of the antibody $\mathrm{V}$ region sequences and subsequent recombinant production in plants. This allows to produce different versions of the antibody, the antibodies produced directly in the 


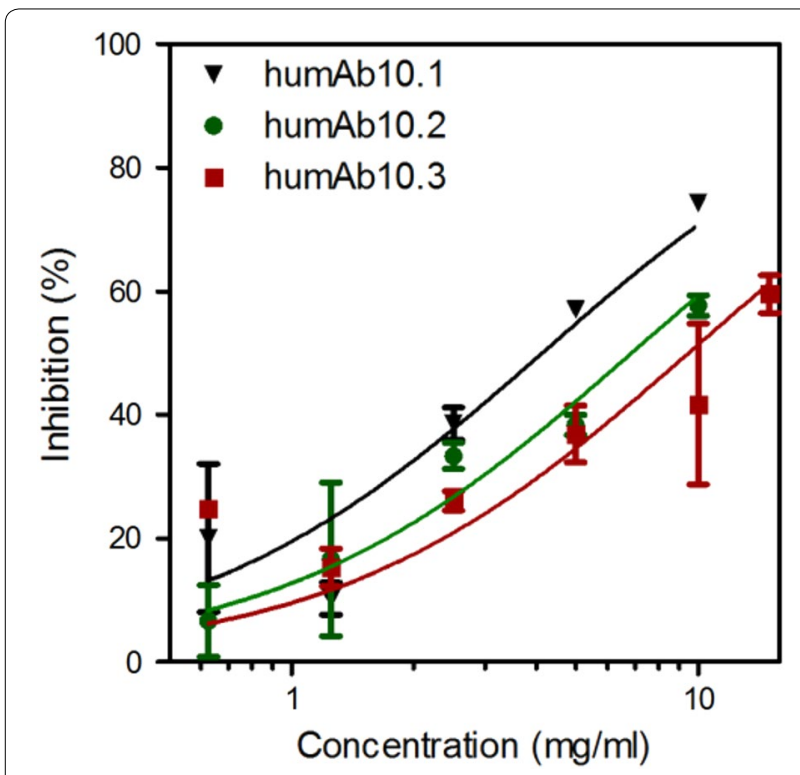

Figure 8 In vitro GIA of P. falciparum 3D7A. Plasmodium falciparum 3D7A had been synchronized three times prior to the start of the GIA at schizont stage. Recombinant humAb10.1 (black triangles), humAb10.2 (green circles) and humAb10.3 (red squares) have been purified by Protein A chromatography, concentrated, re-buffered in culture medium, sterilized by filtration and were applied in final concentrations of up to $10 \mathrm{mg} / \mathrm{ml}$. The plates were harvested after $44 \mathrm{~h}$ and the growth of parasites estimated by a pLDH assay. All tests were carried out in technical triplicates; error bars correspond to standard deviation values.

LCLs, as well as the recombinant antibody. Combinations of different heavy and light chains can only be produced using recombinant antibodies. Moreover, the slight difference in affinity of humAb10.3, which likely relies on posttranslational modifications, can only be detected when comparing multiple expression systems.

The rescue of the antibody variable sequences is especially important, as LCLs tend to cease to secrete antibodies or stop to proliferate altogether, which would lead to an irreversible loss of the desired immunoglobulin [52]. In contrast, the transient antibody production in plants allows for rapid and scalable production, ranging from the infiltration of individual leaves to multiple plants by vacuum infiltration [29,34]. The humAbs described here were produced in this transient production system and showed a yield of more than $100 \mathrm{mg}$ per $\mathrm{kg}$ of plant material. This is in the range of very well producing antibodies which have previously been described $[53,54]$.

The first step of the procedure, the screening of plasma for specific antigen-binding, provides valuable information: On the one hand, the positive reactivity shows that specific antibodies are present in the subjects tested; on the other hand, it validates that the recombinant antigens produced in Nicotiana benthamiana are correctly folded. The general reactivity of these plasma samples against various $P$. falciparum antigens has previously been shown elsewhere [19, 29, 30, 37-39]. Regarding the EGF-like domains of MSP10 described here, in total approx. twothirds of the tested plasma samples reacted with at least one of the two domains. In the case of the other plasmodial EGF-like domains it is also known that these are not recognized by all sera of semi-immune individuals; e.g. the double EGF-like domain of $\mathrm{MSP}_{19}$ [55]. Moreover, the observation that Ghanaian plasma samples primarily reacted with discontinuous epitopes of the EGF-like domains of MSP10 is in line with findings of the first description of the antigen MSP10 [17]. Coherent thereto, the isolated antibodies humAb10.1, humAb10.2 and humAb10.3 just bind to the native antigen and do not recognize reduced MSP10.

It was found that each of the isolated antibody chains had accumulated a considerable number of coding mutations during their affinity maturation in vivo. It can be assumed that it takes 4 years to accumulate 20 mutations in the $\mathrm{Vl}$ and 30 mutations in the $\mathrm{Vh}$ sequences for a desirable affinity maturation to occur [56]. Consequently, it is likely that the in vivo-maturation of humAb10.2 (H5F6:k5F6) and humAb10.3 (H5E8:k5E8) took at least 2-3 years and 3-4 years, respectively. This is well in line with the observation that it takes years for a protective anti-plasmodial immunoglobulin repertoire to arise [6-8].

By ELISA and SPR spectroscopic measurements it was demonstrated that (1) the correct variable regions of LCLs 5E8 and 5F6 were rescued and that (2) the corresponding recombinant IgG1:k full-size antibodies shared the same characteristics with their naturally produced counterparts. It appears that the correct variable sequences had been recovered, cloned and expressed in the context of IgG1:k given the facts that (1) LCLs 5E8 and 5F6 were monoclonal by the time of the rescue of their variable immunoglobulin regions and that (2) naturally and recombinantly produced humAb10.2 and humAb10.3 showed the same respective specificities. Interestingly, the artificial combination H5F6:k5E8 of humAb10.1 featured the same specificity for MSP10(EGF1) as humAb10.2 (H5F6:k5F6). However, humAb10.1 was much less affine for MSP10(EGF1) than humAb10.2 (Table 1). This can likely be explained by the facts that the CDRs of both Vh and Vl regions of each B cell receptor are simultaneously selected for in vivo and that all six CDRs contribute to complementarity, specificity and affinity to the epitope. Thus, the features of a paratope formed by an artificial $\mathrm{Vh}: \mathrm{Vl}$ combination are likely to be compromised and may result in loss of affinity or even specificity. The fact that humAb10.1 still recognized 
MSP10(EGF1) argues for a major role of the heavy chain CDRs in the recognition of MSP10(EGF1). This is in line with the finding that in many antibodies $\mathrm{CDRH} 2$ and CDRH3 contribute most to the free binding energy [57].

IFAs using humAb10.1, humAb10.2 and humAb10.3 showed a fluorescence pattern which closely resembles the one seen before by Black et al. [17]. The antibodies bound to the merozoite surface and marked a specific spot in the region of the apical end of the merozoite. This is consistent with a localization at the rhoptries, the micronemes or a predominant localization at the apical end of the merozoite.

The EGF-like domains of MSP10 are very conserved $[17,58,59]$, which argues for a critical role that does not allow for many changes in amino acid sequence and structure. It is tempting to believe that such invariable epitopes on free merozoites exposed to the serum constitute an Achilles' tendon for inhibitory antibodies. Nevertheless, the inhibitory concentrations of the presented humAbs are relatively high. As compared to other antiplasmodial antibodies, such as AMA1- or Rh5-reactive IgG showing $\mathrm{EC}_{50}$ values of as low as $50-240 \mu \mathrm{g} / \mathrm{ml}[60$, 61], the inhibition of $P$. falciparum by either MSP10-specific humAb thus appears relatively inefficient. To get a more precise idea of the general inhibitory potential of naturally-acquired antibodies against MSP10, it would be highly informative to purify antibodies against MSP10 by affinity purification and subsequently measure their inhibitory potential. Unfortunately, we were not able to perform such an experiment due to the limited availability of the respective plasma samples.

Puentes et al. found three synthetic 20 -mer peptides of MSP10 to be binding to human erythrocytes and to be hampering the invasion of merozoites into erythrocytes in vitro. Interestingly, one of these peptides corresponds to a part of the first EGF-like domain of MSP10 and showed $65 \%( \pm 2 \%)$ inhibition at a concentration of $200 \mu \mathrm{M}(0.46 \mathrm{mg} / \mathrm{ml})$ [18]. The $\mathrm{EC}_{50}$ values of the antibodies described in the present work range from 4.1 to $9.5 \mathrm{mg} / \mathrm{ml}$. This corresponds to a molar concentration range between 27 and $63 \mu \mathrm{M}$. Thus, the $\mathrm{EC}_{50}$ values of the presented humAbs are well below the concentrations needed for the linear peptides of MSP10, but still way above the the $\mathrm{EC}_{50}$ values of some antibodies against AMA1 and or Rh5, as described above. The probable mechanism of the MSP10-specific humAbs is the direct blocking of the binding of the merozoite to the erythrocyte, and thereby inhibiting the attachment/invasion. In case of MSP1, antibodies directed at MSP119, the portion which is comparable to the EGF-like domains of MSP10, can be classified as inhibitory, neutral or blocking (i.e. counteracting the inhibition by other MSP1-specific antibodies) depending on their activity [62]. Given the similarity of the C-terminal parts of MSP1 and MSP10, the question remains which category applies to humAb10.1, humAb10.2. and humAb10.3. As this is the first description of monoclonal antibodies against the antigen MSP10, we cannot make this classification yet for the antibodies described here. The dissection of the actual mechanism would be a valuable subject of further investigations.

However, besides mere binding to the target, antibodies may also fulfil their function in vivo by initiating the complement cascade [63] and/or by recruiting immune effector cells. GIAs, such as the one used in this study, only address direct neutralization capacity. Therefore, it would make sense to perform tests which incorporate monocytes or neutrophil granulocytes [13, 64]. Additionally, it may be possible that the monoclonal antibodies characterized herein cannot completely inhibit the parasite invasion on their own. Rather, they could contribute to a synergistic neutralization when combined with antibodies of different anti-malarial specificities.

Besides a function during attachment to/invasion of new erythrocytes, the EGF-like domains of MSP10 might be carried into the erythrocyte during invasion and might have a function during the development of merozoites into rings. EGF-like domains of MSP1, MSP2 and MSP4 have been reported to stay attached to the merozoite membrane by GPI anchors after processing and to be carried into the freshly infected erythrocyte $[11,65,66]$. It has been assumed that some MSP1 $1_{19}$-specific antibodies may compromise the intraerythrocytic development of Plasmodia [67, 68]. Thus, further studies may address the question if the C-terminal portion of MSP10, which comprises the EGF-like domains, also remains bound to the merozoite until after invasion. This might pave the way for the evaluation of MSP10 as a target of antimalarial fusion proteins [69].

\section{Conclusion}

The presented work describes the generation and characterization of three humAbs which are specific for the first or the second EGF-like domain of MSP10, respectively. To the best of our knowledge this study is the first to combine flow cytometric selection of antigen-specific B cells with EBV transformation and to successfully generate humAbs by this very technique. To our knowledge, these are the first human monoclonal antibodies directed at MSP10, which have been isolated. HumAb10.2 and humAb10.3 possess the genuine combination of corresponding heavy and light chains, respectively; they are highly specific for their corresponding plasmodial EGF-like domain and bind these with high affinity. In in vitro GIAs, the 
MSP10-specific humAbs demonstrated significant inhibition of the parasite strain 3D7A even though comparatively high antibody concentrations were required. Further experiments should address (1), the potential role of immune effector cells in inhibition of merozoites by MSP10-specific antibodies and (2), the identification of interaction partners of MSP10 to deepen understanding of its function(s). The generated humAbs represent a valuable tool to tackle these MSP10 related questions in the future.

\begin{abstract}
Abbreviations
$\mathrm{Vh}$ and $\mathrm{VI}$ sequences: variable sequences of immunoglobulin heavy and light chains; EBV: Epstein-Barr virus; EGF: epidermal growth factor; LCL: Iymphoblastoid cell line; humAb: human monoclonal antibody; CDR: complementarity determining region; $\mathrm{EC}_{50}$ : half-maximal effective concentration; $\mathrm{K}_{\mathrm{D}}$ : dissociation constant; $k_{a}$ : association rate; $k_{d}$ : dissociation rate; IFA: immunofluorescence assay; GIA: growth inhibition assay; ELISA: enzyme-linked immunosorbent assay; GOl: gene of interest.
\end{abstract}

\section{Authors' contributions}

DJMa conceived the study, performed the experiments, analysed the data and wrote the manuscript. SBe, MSe and SKa developed the experimental setup of the rescue of immunoglobulin variable sequences and the GIA. OAM recruited the patients and handled the patient samples. HSp determined the affinity constant of the human and recombinant antibodies, produced the antigens and wrote the manuscript. ABo and GEd produced the antigens and gave scientific advice for the recombinant production of the antibodies. ARe, $\mathrm{RFi}$, and SB conceived the overall study design and contributed to writing the manuscript. TKI and RFe conceived the study, created the study protocol, analysed the data and wrote the manuscript. All authors read and approved the final manuscript.

\begin{abstract}
Author details
${ }^{1}$ Fraunhofer Institute for Molecular Biology and Applied Ecology IME, Aachen, Germany. ${ }^{2}$ Institute for Molecular Biotechnology, RWTH Aachen University, Aachen, Germany. ${ }^{3}$ Faculty of Allied Health Sciences, Kwame Nkrumah University of Science and Technology, Kumasi, Ghana. ${ }^{4}$ Department of Experimental Medicine and Immunotherapy, Institute for Applied Medical Engineering at RWTH Aachen University and Hospital, Aachen, Germany.
\end{abstract}

\section{Acknowledgements}

This work was supported by the "Fraunhofer Zukunftsstiftung". Dominika Maskus was financially supported by the Jürgen Manchot Foundation. Stephanie Kapelski was a stipend of the "RWTH-Graduiertenförderung", and Melanie Seidel was supported by the "Doktorandinnen-Programm" of the Fraunhofer Society. First of all, we would like to thank all blood donors from Ghana and the whole KCCR team from Kumasi/Ghana helping during the study. The p19 suppressor of gene silencing was kindly provided by Plant Bioscience Limited (Norwich, UK) under the terms of an evaluation license agreement. We would also like to thank Thomas Rademacher (Fraunhofer IME, Aachen, Germany) for providing the plasmid pTRAc-p19si and cultivating Nicotiana benthamiana plants. We thank Carmen Franken for big support during all cell culture work. We also wish to thank Mario Losen and Kathleen Vrolix (Maastricht University, The Netherlands) for initially helping us to set up the EBV transformation technique of antigen-specific sorted B cells. Ed Remarque and Bart Faber (BPRC Rijswijk, The Netherlands) generously provided us with AMA1-specific polyclonal rabbit lgG (BG98). The following reagent was obtained through the MR4 as part of the BEI Resources Repository (NIAID, NIH, Bethesda, MD, USA): P. falciparum 3D7A, MRA-151, deposited by D Walliker.

\section{Compliance with ethical guidelines}

\section{Competing interests}

DJMa, SKa, ARe, RFi, SBa, TKI, RFe are named inventors on patent applications describing human anti-malarial antibodies.
Received: 3 March 2015 Accepted: 7 July 2015

Published online: 16 July 2015

\section{References}

1. WHO (2014) World Malaria Report 2014. World Health Organization, Geneva

2. Ramasamy R (1998) Molecular basis for evasion of host immunity and pathogenesis in malaria. Biochim Biophys Acta 1406:10-27

3. Langhorne J, Ndungu FM, Sponaas A, Marsh K (2008) Immunity to malaria: more questions than answers. Nat Immunol 9:725-732. doi:10.1038/ni.f.205

4. Dzikowski R, Deitsch KW (2009) Genetics of antigenic variation in Plasmodium falciparum. Curr Genet 55:103-110. doi:10.1007/s00294-009-0233-2

5. Costa G, Loizon S, Guenot M, Mocan I, Halary F, de Saint-Basile G et al (2011) Control of Plasmodium falciparum erythrocytic cycle: $\gamma \delta$ T cells target the red blood cell-invasive merozoites. Blood 118:6952-6962. doi:10.1182/blood-2011-08-376111

6. Baird JK (1995) Host age as a determinant of naturally acquired immunity to Plasmodium falciparum. Parasitol Today 11:105-111

7. Chelimo K, Ofulla AV, Narum DL, Kazura JW, Lanar DE, John CC (2005) Antibodies to Plasmodium falciparum antigens vary by age and antigen in children in a malaria-holoendemic area of Kenya. Pediatr Infect Dis J 24:680-684

8. Osier FH, Fegan G, Polley SD, Murungi L, Verra F, Tetteh et al (2008) Breadth and magnitude of antibody responses to multiple Plasmodium falciparum merozoite antigens are associated with protection from clinical malaria. Infect Immun 76:2240-2248. doi:10.1128/IAI.01585-07

9. Cohen S, McGregor IA, Carrington S (1961) Gamma-globulin and acquired immunity to human malaria. Nature 192:733-737

10. Sabchareon A, Burnouf T, Ouattara D, Attanath P, Bouharoun-Tayoun H, Chantavanich $P$ et al (1991) Parasitologic and clinical human response to immunoglobulin administration in falciparum malaria. Am J Trop Med Hyg 45:297-308

11. Blackman MJ, Heidrich HG, Donachie S, McBride JS, Holder AA (1990) A single fragment of a malaria merozoite surface protein remains on the parasite during red cell invasion and is the target of invasion-inhibiting antibodies. J Exp Med 172:379-382

12. Bouharoun-Tayoun H, Oeuvray C, Lunel F, Druilhe P (1995) Mechanisms underlying the monocyte-mediated antibody-dependent killing of Plasmodium falciparum asexual blood stages. J Exp Med 182:409-418

13. Kapelski S, Klockenbring T, Fischer R, Barth S, Fendel R (2014) Assessment of the neutrophilic antibody-dependent respiratory burst (ADRB) response to Plasmodium falciparum. J Leukoc Biol 96:1131-1142. doi:10.1189/jlb.4A0614-283RR

14. Roestenberg M, McCall M, Hopman J, Wiersma J, Luty, Adrian JF et al (2009) Protection against a malaria challenge by sporozoite inoculation. N Engl J Med 361:468-477. doi:10.1056/NEJMoa0805832

15. Doolan DL (2011) Plasmodium immunomics. Int J Parasitol 41:3-20. doi:10.1016/j.ijpara.2010.08.002

16. Richards JS, Beeson JG (2009) The future for blood-stage vaccines against malaria. Immunol Cell Biol 87:377-390. doi:10.1038/icb.2009.27

17. Black CG, Wang L, Wu T, Coppel RL (2003) Apical location of a novel EGFlike domain-containing protein of Plasmodium falciparum. Mol Biochem Parasitol 127:59-68

18. Puentes A, Ocampo M, Rodriguez LE, Vera R, Valbuena J, Curtidor H et al (2005) Identifying Plasmodium falciparum merozoite surface protein-10 human erythrocyte specific binding regions. Biochimie 87:461-472. doi:10.1016/j.biochi.2005.01.001

19. Voepel N, Boes A, Edgue G, Beiss V, Kapelski S, Reimann A et al (2014) Malaria vaccine candidate antigen targeting the pre-erythrocytic stage of Plasmodium falciparum produced at high level in plants. Biotechnol J 9:1435-1445. doi:10.1002/biot.201400350

20. Mordmüller B, Szywon K, Greutelaers B, Esen M, Mewono L, Treut C et al (2010) Safety and immunogenicity of the malaria vaccine candidate GMZ2 in malaria-exposed, adult individuals from Lambarene Gabon. Vaccine 28:6698-6703. doi:10.1016/j.vaccine.2010.07.085 
21. Team RC (2013) R: a language and environment for statistical computing. R Foundation for Statistical Computing. European Environment Agency, Copenhagen, Denmark, Vienna

22. Fraussen J, Vrolix K, Martinez-Martinez P, Losen M, Meulemans E, De Baets $\mathrm{MH}$ et al (2010) A novel method for making human monoclonal antibodies. J Autoimmun 35:130-134. doi:10.1016/j.jaut.2010.05.001

23. Tiller T, Meffre E, Yurasov S, Tsuiji M, Nussenzweig MC, Wardemann H (2008) Efficient generation of monoclonal antibodies from single human B cells by single cell RT-PCR and expression vector cloning. J Immunol Methods 329:112-124. doi:10.1016/j.jim.2007.09.017

24. Brochet X, Lefranc M, Giudicelli V (2008) IMGTN-QUEST: the highly customized and integrated system for IG and TR standardized V-J and V-D-J sequence analysis. Nucleic Acids Res 36:W503-W508. doi:10.1093/nar/ gkn316

25. Stothard P (2000) The sequence manipulation suite: javaScript programs for analyzing and formatting protein and DNA sequences. Biotechniques 28(1102):1104

26. Martin ACR (2001) Protein sequence and structure analysis of antibody variable domains. In: Kontermann R, Dübel S (eds) Antibody Engineering. Springer, Heidelberg, pp 33-51. doi:10.1007/978-3-642-01147-4_3

27. Sievers F, Wilm A, Dineen D, Gibson TJ, Karplus K, Li W et al (2011) Fast, scalable generation of high-quality protein multiple sequence alignments using Clustal Omega. Mol Syst Biol 7:539. doi:10.1038/msb.2011.75

28. Monigatti F, Gasteiger E, Bairoch A, Jung E (2002) The Sulfinator: predicting tyrosine sulfation sites in protein sequences. Bioinformatics 18:769-770

29. Kapelski S, Boes A, Spiegel H, de Almeida M, Klockenbring T, Reimann A et al (2015) Fast track antibody V-gene rescue, recombinant expression in plants and characterization of a Pf MSP4-specific antibody. Malar J 14:50. doi:10.1186/s12936-015-0577-7

30. Feller T, Thom P, Koch N, Spiegel H, Addai-Mensah O, Fischer R et al (2013) Plant-based production of recombinant Plasmodium surface protein pf38 and evaluation of its potential as a vaccine candidate. PLoS One 8:e79920. doi:10.1371/journal.pone.0079920

31. Trager W, Jensen JB (1976) Human malaria parasites in continuous culture. Science 193:673-675

32. Remarque EJ, Faber BW, Kocken, Clemens HM, Thomas AW (2008) A diversity-covering approach to immunization with Plasmodium falciparum apical membrane antigen 1 induces broader allelic recognition and growth inhibition responses in rabbits. Infect Immun 76:2660-2670. doi:10.1128/IAl.00170-08

33. Faber BW, Younis S, Remarque EJ, Rodriguez Garcia R, Riasat V, Walraven V et al (2013) Diversity covering AMA1-MSP119 fusion proteins as malaria vaccines. Infect Immun 81:1479-1490. doi:10.1128/IAI.01267-12

34. Rosenberg Y, Sack M, Montefiori D, Forthal D, Mao L, Hernandez-Abanto S et al (2013) Rapid high-level production of functional HIV broadly neutralizing monoclonal antibodies in transient plant expression systems. PLoS One 8:e58724. doi:10.1371/journal.pone.0058724

35. Radfar A, Mendez D, Moneriz C, Linares M, Marin-Garcia P, Puyet A et al (2009) Synchronous culture of Plasmodium falciparum at high parasitemia levels. Nat Protoc 4:1899-1915. doi:10.1038/nprot.2009.198

36. Kennedy MC, Wang J, Zhang Y, Miles AP, Chitsaz F, Saul A et al (2002) In vitro studies with recombinant Plasmodium falciparum apical membrane antigen 1 (AMA1): production and activity of an AMA1 vaccine and generation of a multiallelic response. Infect Immun 70:6948-6960

37. Beiss V, Spiegel H, Boes A, Kapelski S, Scheuermayer M, Edque G et al (2015) Heat-precipitation allows the efficient purification of a functional plant-derived malaria transmission-blocking vaccine candidate fusion protein. Biotechnol Bioeng. doi:10.1002/bit.25548

38. Boes A, Spiegel H, Edgue G, Kapelski S, Scheuermayer M, Fendel R et al (2015) Detailed functional characterization of glycosylated and nonglycosylated variants of malaria vaccine candidate PfAMA1 produced in Nicotiana benthamiana and analysis of growth inhibitory responses in rabbits. Plant Biotechnol J 13:222-234. doi:10.1111/pbi.12255

39. Spiegel $H$, Schinkel $H$, Kastilan $R$, Dahm P, Boes $A$, Scheuermayer $M$ et al (2014) Optimization of a multi-stage, multi-subunit malaria vaccine candidate for the production in Pichia pastoris by the identification and removal of protease cleavage sites. Biotechnol Bioeng. doi:10.1002/ bit.25481
40. Egan AF, Chappel JA, Burghaus PA, Morris JS, McBride JS, Holder AA et al (1995) Serum antibodies from malaria-exposed people recognize conserved epitopes formed by the two epidermal growth factor motifs of MSP1(19), the carboxy-terminal fragment of the major merozoite surface protein of Plasmodium falciparum. Infect Immun 63:456-466

41. Wang L, Black CG, Marshall VM, Coppel RL (1999) Structural and antigenic properties of merozoite surface protein 4 of Plasmodium falciparum. Infect Immun 67:2193-2200

42. Moore KL (2009) Protein tyrosine sulfation: a critical posttranslation modification in plants and animals. Proc Natl Acad Sci USA 106:14741-14742. doi:10.1073/pnas.0908376106

43. Cheng X, Hayasaka H, Watanabe K, Tao Y, Liu J, Tsukamoto H et al (2007) Production of high-affinity human monoclonal antibody fab fragments to the 19-kilodalton C-terminal merozoite surface protein 1 of Plasmodium falciparum. Infect Immun 75:3614-3620. doi:10.1128/IAl.00062-07

44. Stubbs J, Olugbile S, Saidou B, Simpore J, Corradin G, Lanzavecchia A (2011) Strain-transcending Fc-dependent killing of Plasmodium falciparum by merozoite surface protein 2 allele-specific human antibodies. Infect Immun 79:1143-1152. doi:10.1128/IAI.01034-10

45. Lundquist R, Nielsen LK, Jafarshad A, Soesoe D, Christensen LH, Druilhe $P$ et al (2006) Human recombinant antibodies against Plasmodium falciparum merozoite surface protein 3 cloned from peripheral blood leukocytes of individuals with immunity to malaria demonstrate antiparasitic properties. Infect Immun 74:3222-3231. doi:10.1128/IAI.00928-05

46. Muellenbeck MF, Ueberheide B, Amulic B, Epp A, Fenyo D, Busse CE et al (2013) Atypical and classical memory B cells produce Plasmodium falciparum neutralizing antibodies. J Exp Med 210:389-399. doi:10.1084/ jem.20121970

47. Barfod L, Bernasconi NL, Dahlback M, Jarrossay D, Andersen PH, Salanti A et al (2007) Human pregnancy-associated malaria-specific B cells target polymorphic, conformational epitopes in VAR2CSA. Mol Microbiol 63:335-347. doi:10.1111/j.1365-2958.2006.05503.x

48. Udomsangpetch $\mathrm{R}$, Lundgren $\mathrm{K}$, Berzins $\mathrm{K}$, Wahlin $\mathrm{B}$, Perlmann $\mathrm{H}$, Troye-Blomberg M et al (1986) Human monoclonal antibodies to Pf 155, a major antigen of malaria parasite Plasmodium falciparum. Science 231:57-59

49. Kim S, Hwang S, Lee Y, Choi I, Park S, Kho W (2007) Single-chain antibody fragment specific for Plasmodium vivax Duffy binding protein. Clin Vaccine Immunol 14:726-731. doi:10.1128/CVI.00456-06

50. Roeffen WF, Raats JM, Teelen K, Hoet RM, Eling WM, van Venrooij WJ et al (2001) Recombinant human antibodies specific for the Pfs $48 / 45$ protein of the malaria parasite Plasmodium falciparum. J Biol Chem 276:1980719811. doi:10.1074/jbc.M100562200

51. Chappel JA, Rogers WO, Hoffman SL, Kang AS (2004) Molecular dissection of the human antibody response to the structural repeat epitope of Plasmodium falciparum sporozoite from a protected donor. Malar J 3:28. doi:10.1186/1475-2875-3-28

52. Glasky MS, Reading CL (1989) Stability of specific immunoglobulin secretion by EBV-transformed lymphoblastoid cells and human-murine heterohybridomas. Hybridoma 8:377-389

53. Strasser R, Stadlmann J, Schahs M, Stiegler G, Quendler H, Mach L et al (2008) Generation of glyco-engineered Nicotiana benthamiana for the production of monoclonal antibodies with a homogeneous human-like N-glycan structure. Plant Biotechnol J 6:392-402. doi:10.1111/j.1467-7652.2008.00330.x

54. Both L, van Dolleweerd C, Wright E, Banyard AC, Bulmer-Thomas B, Selden D et al (2013) Production, characterization, and antigen specificity of recombinant 62-71-3, a candidate monoclonal antibody for rabies prophylaxis in humans. FASEB J. 27:2055-2065. doi:10.1096/f.12-219964

55. Taylor RR, Egan A, McGuinness D, Jepson A, Adair R, Drakely C et al (1996) Selective recognition of malaria antigens by human serum antibodies is not genetically determined but demonstrates some features of clonal imprinting. Int Immunol 8:905-915

56. Doria-Rose NA, Schramm CA, Gorman J, Moore PL, Bhiman JN, DeKosky BJ et al (2014) Developmental pathway for potent V1V2-directed HIVneutralizing antibodies. Nature 509:55-62. doi:10.1038/nature13036

57. Robin G, Sato Y, Desplancq D, Rochel N, Weiss E, Martineau P (2014) Restricted diversity of antigen binding residues of antibodies revealed by computational alanine scanning of 227 antibody-antigen complexes. J Mol Biol 426:3729-3743. doi:10.1016/j.jmb.2014.08.013 
58. Tetteh, Kevin KA, Stewart LB, Ochola LI, Amambua-Ngwa A, Thomas AW, Marsh K et al (2009) Prospective identification of malaria parasite genes under balancing selection. PLoS One 4:5568. doi:10.1371/journal. pone.0005568

59. Pacheco MA, Elango AP, Rahman AA, Fisher D, Collins WE, Barnwell JW et al (2012) Evidence of purifying selection on merozoite surface protein 8 (MSP8) and 10 (MSP10) in Plasmodium spp.. Infect Genet Evol 12:978-986. doi:10.1016/j.meegid.2012.02.009

60. Miura K, Zhou H, Diouf A, Moretz SE, Fay MP, Miller LH et al (2009) Antiapical-membrane-antigen-1 antibody is more effective than anti-42-kilodalton-merozoite-surface-protein-1 antibody in inhibiting Plasmodium falciparum growth, as determined by the in vitro growth inhibition assay. Clin Vaccine Immunol 16:963-968. doi:10.1128/CVI.00042-09

61. Douglas AD, Williams AR, Knuepfer E, Illingworth JJ, Furze JM, Crosnier C et al (2014) Neutralization of Plasmodium falciparum merozoites by antibodies against PfRH5. J Immunol 192:245-258. doi:10.4049/ jimmunol.1302045

62. Guevara JA, Holder AA, McBride JS, Blackman MJ (1997) Antibodies that inhibit malaria merozoite surface protein-1 processing and erythrocyte invasion are blocked by naturally acquired human antibodies. J Exp Med 186:1689-1699

63. Boyle MJ, Reiling L, Feng G, Langer C, Osier FH, Aspeling-Jones $\mathrm{H}$ et al (2015) Human antibodies fix complement to inhibit Plasmodium falciparum invasion of erythrocytes and are associated with protection against malaria. Immunity 42:580-590. doi:10.1016/j.immuni.2015.02.012
64. Druilhe P, Spertini F, Soesoe D, Corradin G, Mejia P, Singh S et al (2005) A malaria vaccine that elicits in humans antibodies able to kill Plasmodium falciparum. PLoS Med 2:e344. doi:10.1371/journal.pmed.0020344

65. Blackman MJ, Ling IT, Nicholls SC, Holder AA (1991) Proteolytic processing of the Plasmodium falciparum merozoite surface protein-1 produces a membrane-bound fragment containing two epidermal growth factorlike domains. Mol Biochem Parasitol 49:29-33

66. Boyle MJ, Langer C, Chan J, Hodder AN, Coppel RL, Anders RF et al (2014) Sequential processing of merozoite surface proteins during and after erythrocyte invasion by Plasmodium falciparum. Infect Immun 82:924-936. doi:10.1128/IAI.00866-13

67. Bergmann-Leitner ES, Duncan EH, Angov E (2009) MSP-1p42-specific antibodies affect growth and development of intra-erythrocytic parasites of Plasmodium falciparum. Malar J 8:183. doi:10.1186/1475-2875-8-183

68. Moss DK, Remarque EJ, Faber BW, Cavanagh DR, Arnot DE, Thomas AW et al (2012) Plasmodium falciparum 19-kilodalton merozoite surface protein 1 (MSP1)-specific antibodies that interfere with parasite growth in vitro can inhibit MSP1 processing, merozoite invasion, and intracelIular parasite development. Infect Immun 80:1280-1287. doi:10.1128/ |Al.05887-11

69. Kapelski S, de Almeida M, Fischer R, Barth S, Fendel R (2015) Antimalarial activity of granzyme $B$ and its targeted delivery by a granzyme B-singlechain fv fusion protein. Antimicrob Agents Chemother 59:669-672. doi:10.1128/AAC.04190-14

\section{Submit your next manuscript to BioMed Central and take full advantage of:}

- Convenient online submission

- Thorough peer review

- No space constraints or color figure charges

- Immediate publication on acceptance

- Inclusion in PubMed, CAS, Scopus and Google Scholar

- Research which is freely available for redistribution

Submit your manuscript at

www.biomedcentral.com/submit

C Biomed Central 